University of Nebraska - Lincoln

DigitalCommons@University of Nebraska - Lincoln

2019

\title{
A Methodology for Flash Drought Identification: Application of Flash Drought Frequency across the United States
}

Jordan I. Christian

University of Oklahoma, Norman

Jeffery B. Basara

University of Oklahoma, Norman

Jason A. Otkin

niversity of Wisconsin-Madison

Eric D. Hunt

Atmospheric and Environmental Research, Inc., Lexington

Ryann A. Wakefield

University of Oklahoma, Norman

See next page for additional authors

Follow this and additional works at: https://digitalcommons.unl.edu/natrespapers

Part of the Natural Resources and Conservation Commons, Natural Resources Management and Policy Commons, and the Other Environmental Sciences Commons

Christian, Jordan I.; Basara, Jeffery B.; Otkin, Jason A.; Hunt, Eric D.; Wakefield, Ryann A.; Flanagan, Paul X.; and Xiao, Xiangming, "A Methodology for Flash Drought Identification: Application of Flash Drought Frequency across the United States" (2019). Papers in Natural Resources. 1235.

https://digitalcommons.unl.edu/natrespapers/1235

This Article is brought to you for free and open access by the Natural Resources, School of at DigitalCommons@University of Nebraska - Lincoln. It has been accepted for inclusion in Papers in Natural Resources by an authorized administrator of DigitalCommons@University of Nebraska - Lincoln. 


\section{Authors}

Jordan I. Christian, Jeffery B. Basara, Jason A. Otkin, Eric D. Hunt, Ryann A. Wakefield, Paul X. Flanagan, and Xiangming Xiao 


\title{
A Methodology for Flash Drought Identification: Application of Flash Drought Frequency across the United States
}

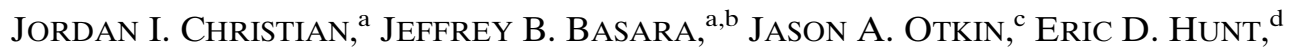 \\ Ryann A. WAKefield, ${ }^{a}$ PAUl X. Flanagan, ${ }^{\mathrm{a}, \mathrm{e}}$ AND Xiangming XiaO ${ }^{\mathrm{f}}$ \\ ${ }^{\text {a }}$ School of Meteorology, University of Oklahoma, Norman, Oklahoma \\ ${ }^{\mathrm{b}}$ School of Civil Engineering and Environmental Science, University of Oklahoma, Norman, Oklahoma \\ ${ }^{\mathrm{c}}$ Cooperative Institute for Meteorological Satellite Studies, Space Science and Engineering Center, University of \\ Wisconsin-Madison, Madison, Wisconsin \\ ${ }^{\mathrm{d}}$ Atmospheric and Environmental Research, Inc., Lexington, Massachusetts \\ ${ }^{\mathrm{e}}$ High Plains Regional Climate Center, School of Natural Resources, University of Nebraska-Lincoln, Lincoln, Nebraska \\ ${ }^{\mathrm{f}}$ Department of Microbiology and Plant Biology, Center of Spatial Analysis, University of Oklahoma, Norman, Oklahoma
}

(Manuscript received 11 September 2018, in final form 26 February 2019)

\begin{abstract}
With the increasing use of the term "flash drought" within the scientific community, Otkin et al. provide a general definition that identifies flash droughts based on their unusually rapid rate of intensification. This study presents an objective percentile-based methodology that builds upon that work by identifying flash droughts using standardized evaporative stress ratio (SESR) values and changes in SESR over some period of time. Four criteria are specified to identify flash droughts: two that emphasize the vegetative impacts of flash drought and two that focus on the rapid rate of intensification. The methodology was applied to the North American Regional Reanalysis (NARR) to develop a 38-yr flash drought climatology (1979-2016) across the United States. It was found that SESR derived from NARR data compared well with the satellite-based evaporative stress index for four previously identified flash drought events. Furthermore, four additional flash drought cases were compared with the U.S. Drought Monitor (USDM), and SESR rapidly declined 1-2 weeks before a response was evident with the USDM. From the climatological analysis, a hot spot of flash drought occurrence was revealed over the Great Plains, the Corn Belt, and the western Great Lakes region. Relatively few flash drought events occurred over mountainous and arid regions. Flash droughts were categorized based on their rate of intensification, and it was found that the most intense flash droughts occurred over the central Great Plains, Corn Belt, and western Great Lakes region.
\end{abstract}

\section{Introduction}

Drought is one of the most costly natural disasters (Wilhite 2000) with complex impacts that can impose significant economic, environmental, and social stress (Wilhite et al. 2007). While preferred regions exist within the United States for drought development and persistence, drought occurrence is possible anywhere in the country (Diaz 1983). Furthermore, the impacts of drought are extensive, with diverse ramifications specific to different regions across the United States (Basara et al. 2013; Manuel 2008; Griffin and Anchukaitis 2014; Zou et al. 2018). These primary impacts include agriculture, surface and groundwater availability, recreation, human

\footnotetext{
Corresponding author: Jordan I. Christian, jchristian@ou.edu
}

health, wildfires, and ecosystems (Basara et al. 2013; Westerling and Swetnam 2003; Krishnan et al. 2006). In addition to impacts, the drivers of drought are similarly diverse, including shifts in atmospheric patterns, anomalous sea surface temperatures, and land-atmosphere coupling (Chang and Wallace 1987; McCabe et al. 2008; Basara and Christian 2018).

While drought is generally described as slowly developing (Wilhite et al. 2007), recent studies have unveiled a new type of rapidly developing drought: flash drought. Within the context of the four traditional drought classifications (meteorological, agricultural, hydrological, and socioeconomic; Wilhite and Glantz 1985), flash droughts often begin as a meteorological drought that then transitions to agricultural drought as conditions continue to deteriorate. If extreme atmospheric 
anomalies (i.e., lack of rainfall, higher surface temperatures, strong winds, and clear skies) persist for several weeks, the onset and development of drought can occur rapidly. Flash drought is critically important to understand as rapid drought intensification can occur regardless of preceding moisture conditions. For example, even though environmental conditions were near normal at the end of May 2012, the flash drought event across the central United States during the growing season of 2012 was associated with three-, four-, and five-category increases in the U.S. Drought Monitor (USDM; Svoboda et al. 2002; Otkin et al. 2018a). Further, flash droughts induce large impacts on agriculture and can stress short-term water resources through rapid deterioration of vegetation health and rapid depletion of soil moisture. Heat waves may also manifest during flash droughts, which can further lead to significant impact on agricultural yields and loss of life (Mo and Lettenmaier 2015; Thacker et al. 2008).

Rapid drought intensification is also difficult to predict as flash droughts are subseasonal phenomena and the complex drivers are not fully understood (Otkin et al. 2018a). As such, it is critical to understand where flash drought events are most likely to occur to improve predictability and to know where impacts from flash drought are most common. Flash droughts were initially examined in Otkin et al. (2013) using the satellite-based evaporative stress index (ESI; Anderson et al. 2007a,b). The relationship between rapid drought development and changes in ESI was further explored in Otkin et al. (2014) where they showed that the rapid change index (RCI) derived from temporal changes in the ESI can provide early warning of agricultural flash drought. More recently, the evaporative demand drought index (EDDI) has been used as a flash drought indicator (Hobbins et al. 2016). EDDI leverages atmospheric demand to not only detect and track drought, but to provide an early warning indicator of rapid onset drought development (McEvoy et al. 2016). Flash drought events have also been examined by using belownormal soil moisture values. For example, Yuan et al. (2018) used rapid declines in soil moisture to investigate the spatiotemporal distribution of flash drought over southern Africa while Wang et al. (2016) used temperature, soil moisture, and evapotranspiration anomalies to examine trends in flash droughts across China. Further, Ford and Labosier (2017) investigated the meteorological conditions associated with flash drought in the eastern United States.

With the increasing usage of the term flash drought in the scientific community, a general definition for these features of the climate system was provided by Otkin et al. (2018a) that is based on rate of intensification.
While previous studies (e.g., Mo and Lettenmaier 2015, 2016; Zhang et al. 2017) have placed an emphasis on short duration for flash drought identification, Otkin et al. (2018a) argue that identification of flash droughts based on criteria for a short duration deviates from the fundamental drought characteristics of longevity and impact. The general definition of flash drought presented in Otkin et al. (2018a) called for an objective, statistical methodology to identify flash drought events. Therefore, the purpose of this study is twofold: 1) to create a consistent statistical methodology that can be used to identify flash drought cases in any gridded dataset containing evapotranspiration (ET) and potential evapotranspiration (PET), or their constituents, and 2) to apply the methodology to a reanalysis dataset to investigate the climatological characteristics of flash droughts across the United States.

\section{Flash drought identification methodology}

\section{a. Standardized evaporative stress ratio}

The foundation of flash drought identification proposed in this study relies upon the evaporative stress ratio (ESR). ET and PET are used to calculate ESR, such that

$$
\mathrm{ESR}=\frac{\mathrm{ET}}{\mathrm{PET}}
$$

where ESR ranges from zero to approximately one. The interpretation of ESR is as follows: as ESR approaches one, the atmospheric demand of ET is met by the available soil moisture and vegetation; as ESR approaches zero, the land surface meets little or none of the atmospheric demand. Thus, the value of ESR is inversely proportional to the amount of evaporative stress on the environment. The satellite-derived ESI (similar to standardized ESR) has been widely used in studies examining drought processes including comparison of ESI with leaf area index and precipitation anomalies, utilizing ESI as an indicator for agricultural drought, and an intercomparison of ESI with soil moisture, ET, and runoff anomalies from reanalysis data (Anderson et al. 2011, 2013, 2015, 2016a,b; Otkin et al. 2013, 2016, 2018b, 2019). As such, ESR was selected for flash drought analysis as it directly incorporates near-surface state variables including air temperature, wind speed, vapor pressure deficit, latent and sensible heat fluxes, as well as soil moisture, precipitation, and shortwave radiation, and follows the guidance of Otkin et al. (2018a).

For flash drought identification, standardized ESR (SESR) values are used to more easily compare the evaporative stress between regions characterized by different 
climate regimes. Such standardization also allows a more robust comparison of ESR values over multiple years and parts of the growing season for each grid point. Before SESR values are calculated, mean pentad values of ESR are computed. It is highly recommended to use pentad (or longer) time periods when computing SESR due to the volatility that is sometimes present in daily ESR. Computing pentad values smooths out short-term fluctuations in ESR and allows the development of an objective methodology for flash drought identification. As a result, the remaining description of flash drought identification is based on pentad values of ESR. An illustration of the standardization process is shown in Fig. 1. First, pentad SESR values are computed for each grid point,

$$
\mathrm{SESR}_{i j p}=\frac{\mathrm{ESR}_{i j p}-\overline{\mathrm{ESR}_{i j p}}}{\sigma_{\mathrm{ESR}_{i j p}}},
$$

where $\mathrm{SESR}_{i j p}$ (henceforth referred to as SESR) is the $z$ score of ESR for a specific pentad $p$ at a specific grid point $(i, j), \overline{\mathrm{ESR}}$ is the mean ESR for a specific pentad $p$ at a specific grid point $(i, j)$ for all years available in the gridded dataset, and $\sigma_{\mathrm{ESR}}$ is the standard deviation of ESR for a specific pentad $p$ at a specific grid point $(i, j)$ for all years available in the gridded dataset. This standardization is similar to that for ESI (e.g., Anderson et al. 2011; Otkin et al. 2013, 2014) where ESI was standardized for each week at each grid point.

A critical characteristic of flash drought identification involves the "flash" component representing rapid drought intensification. This is derived by calculating the change in SESR values between each pentad. The change in SESR is standardized in the same way as ESR, similar to the standardization of ESI changes in prior studies by Anderson et al. (2013) and Otkin et al. (2013, 2014). In this analysis, the standardized change in SESR is given as

$$
\left(\Delta \operatorname{SESR}_{i j p}\right)_{z}=\frac{\Delta \operatorname{SESR}_{i j p}-\overline{\Delta \operatorname{SESR}_{i j p}}}{\sigma_{\Delta \operatorname{SESR}_{i j p}}}
$$

where $\left(\Delta \operatorname{SESR}_{i j p}\right)_{z}$ (henceforth referred to as $\Delta \mathrm{SESR}$ ) is the $z$ score of the change in SESR for a specific pentad $p$ at a specific grid point $(i, j), \overline{\Delta \text { SESR }}$ is the mean change in SESR values for a specific pentad $p$ at a specific grid point $(i, j)$ for all years available in the gridded dataset, and $\sigma_{\triangle \mathrm{SESR}}$ is the standard deviation of SESR for a specific pentad $p$ at a specific grid point $(i, j)$ for all years available in the gridded dataset. It is important to note that this process is applied to all land grid points in the dataset.

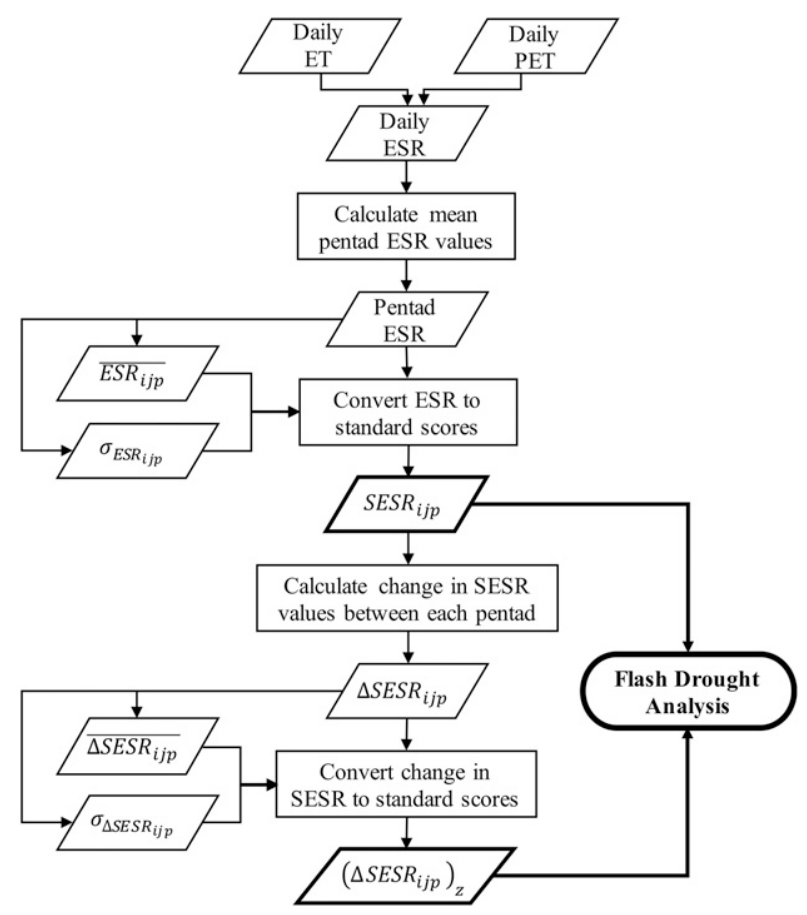

FIG. 1. A schematic of the standardization process to obtain $\mathrm{SESR}_{i j p}$ (referred to as SESR) and $\left(\Delta \mathrm{SESR}_{i j p}\right)_{z}$ (referred to as $\Delta$ SESR). Subscript indices $i$ and $j$ represent grid point locations, and $p$ represents a specific pentad.

\section{b. Flash drought identification}

Four criteria involving SESR are used to identify flash drought events. The first two criteria are used to address the impacts of flash drought on the environment while the latter two criteria emphasize the rapid rate of drought intensification. In this methodology, flash drought events are required to have 1) a minimum length of five SESR changes ( $\triangle$ SESR), equivalent to a length of six pentads (30 days), and 2) a final SESR value below the 20th percentile of SESR values. Both of these criteria are founded upon characteristics of flash droughts described in Otkin et al. (2018a). The minimum length of 30 days for criterion 1 was selected based off the previously defined temporal definition of flash droughts provided in Otkin et al. (2018a), and the length of flash droughts depicted in case studies from Otkin et al. (2013). Otkin et al. (2018a) states that the minimum time frame in which flash droughts develop is over the course of "several weeks." Furthermore, each of the flash drought cases examined in Otkin et al. (2013) were a minimum length of 30 days or longer. As such, the combination of this definition and the resulting case studies determined the minimum length of a flash drought defined for criterion 1 . The emphasis of criterion 1 is the elimination of short-term dry spells so 
that the definition captures situations where drought impacts occur (i.e., significant reduction of water resources including soil moisture, stress to the ecosystem, etc.). A rapid change in SESR from one pentad to the next by itself does not necessarily indicate an impact to the ecosystem and environment unless below-average SESR values persist for a longer period of time. Adverse impacts on the environment are most likely to occur when there is continuous rapid development toward drought conditions from one pentad to the next. Regarding criterion 2, Otkin et al. (2018a) states that any variable used to identify flash droughts must fall below the 20th percentile for it to be considered drought. Criterion 2 satisfies the drought component of this definition by requiring that, at a minimum, drought conditions occur by the end of the rapid intensification period.

Regarding the rate of rapid drought intensification, two criteria are used: one that focuses on pentad-topentad changes toward drought development (criterion 3) and another that emphasizes rapid drought development through the entirety of the flash drought event (criterion 4). Criterion 3 contains the following two components:

1) criterion 3a: $\triangle$ SESR must be at or below the 40th percentile between individual pentads, and

2) criterion $3 \mathrm{~b}$ : no more than one $\triangle$ SESR above the 40th percentile following a $\triangle$ SESR that meets criterion $3 a$.

If criterion $3 \mathrm{~b}$ is reached, then the following $\triangle \mathrm{SESR}$ must meet criterion $3 \mathrm{a}$ and have an ending SESR value less than the SESR value preceding the SESR moderation in order for the flash drought to continue. The end of a flash drought is attained at the last pentad for which criterion $3 \mathrm{a}$ is satisfied.

The fourth criterion complements the third criterion and is applied to the entire length of the flash drought (beginning from the first pentad where criterion $3 \mathrm{a}$ is met and ending at the last pentad in which criterion $3 \mathrm{a}$ is met). Specifically, the mean change in SESR during the entire length of the flash drought must be less than the 25th percentile of the climatological changes in SESR for that grid point and time of year. This criterion is used to ensure that features identified as flash droughts have an overall rapid rate of development of drought conditions and are not significantly slowed by temporary moderations of SESR due to the effects of precipitation, lower temperatures, more cloud coverage, or lower surface wind speeds. It is important to note that for all percentile values used in criteria 2 and 3, percentiles were taken from the distribution of SESR and $\triangle$ SESR at local grid points and specific pentads for all years available in the dataset. For criterion 4, percentiles were calculated from the distribution of $\triangle$ SESR at local grid points for pentads that were encompassed within the flash drought event.

The threshold percentile for individual pentad-topentad SESR changes (40th percentile) is more lenient than the threshold percentile for overall SESR change (25th percentile) during the entire length of the flash drought event for two reasons. First, the 40th percentile was used to separate periods of worsening conditions (less than 40th percentile) from those characterized by nearly constant or improving conditions (greater than 40th percentile) during changes between individual pentads. Second, during an extended period of rapid drought intensification, some pentad changes in SESR will exhibit very rapid development (e.g., less than the 10th percentile) while others will experience slower intensification (e.g., 35th percentile). The more lenient 40th percentile threshold for pentad-to-pentad changes accounts for these variations in rapid intensification, while working in tandem with criterion 4 to ensure the average change in SESR throughout the flash drought event is rapid.

To illustrate the four criteria in action for identifying a flash drought event, a time series schematic is presented in Fig. 2. In this example, a flash drought event was identified from mid-June to mid-July. The beginning of rapid drought intensification begins on 11 June, with a $\triangle$ SESR at the 26th percentile. The subsequent two $\triangle$ SESR on 16 and 21 June also remain below the 40th percentile, listed as criterion $3 \mathrm{a}$. On 26 June, $\triangle$ SESR is at the 67th percentile. This $\triangle$ SESR is identified as a period of moderation and the subsequent $\triangle$ SESR is examined to see if it falls below the 40th percentile. The following $\triangle$ SESR on 1 July is at the 9th percentile. Furthermore, the SESR value at the end of the $\triangle$ SESR (identified as P6 in Fig. 2) is less than the SESR value before the period of moderation began (identified as P4). This satisfies criterion $3 \mathrm{~b}$, and the flash drought continues. The next $\triangle$ SESR on 6 July is at the 27 th percentile and satisfies criterion $3 \mathrm{a}$. On $11 \mathrm{July}$, the $\triangle$ SESR is at the 58th percentile, and the following $\triangle$ SESR is at the 43 rd percentile. Therefore, the end of rapid drought intensification ends on 11 July. The remaining three criteria are used to complete the identification process. First, the flash drought event illustrated in the schematic is $6 \Delta$ SESR or 7 total pentads long. This satisfies criterion 1 for the minimum length of a flash drought event. Next, the final SESR value of the rapid intensification period is identified as $\mathrm{P} 7$ on the time series. An example 20th percentile of SESR is shown to be approximately -0.8 , such that criterion 2 is met for the "drought" component of flash drought. Last, the mean $\triangle$ SESR for the flash drought event is 


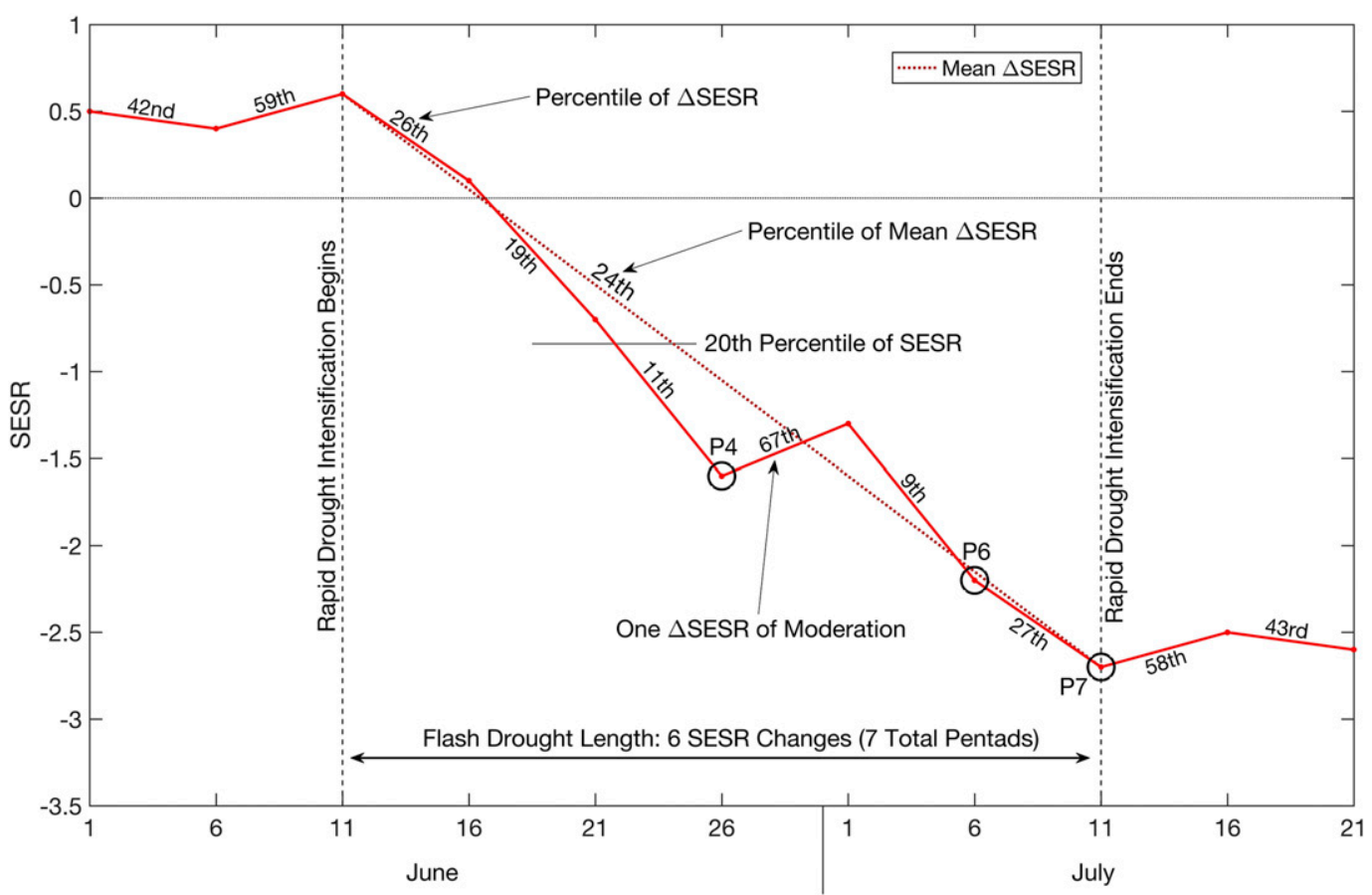

FIG. 2. A time series schematic illustrating the four criteria used in the flash drought identification methodology.

calculated to verify that any moderation periods within the flash drought did not significantly impede rapid drought intensification. The mean $\triangle$ SESR is found to be at the 24th percentile, meeting the requirement outlined in criterion 4. Therefore, this rapid drought intensification period satisfies all of the criteria to be identified as a flash drought event.

A generalized flowchart of the flash drought identification process is shown in Fig. 3. Two separate elements are noted in this methodology. The top left side of the schematic represents the rapid rate of intensification toward drought. This is encompassed within criterion 3a of the flash drought methodology. The top right side of the schematic represents an inclusion of moderation within the identification of a flash drought. This is composed within criterion $3 \mathrm{~b}$ and accounts for brief periods in which a rapid decrease in SESR values (increase in evaporative stress) is limited by precipitation, lower temperatures, and any other set of environmental processes that reduces overall evaporative stress. In the methodology provided here, only one pentad of moderation is permitted because if two or more consecutive pentads of moderation are allowed, it is more likely that conventional droughts (slowly developing) will be erroneously identified as flash droughts. Given that the onset and development of flash drought is on the order of several weeks to a couple of months (Otkin et al. 2018a), inclusion of long periods of moderation is inconsistent with the definition of flash drought.

\section{Evaluation of the flash drought methodology}

\section{a. Dataset}

To demonstrate the methodology, data from the National Centers for Environmental Prediction North American Regional Reanalysis (NCEP NARR; Mesinger et al. 2006) were used. While limited studies exist comparing land surface variables in NARR with observations, NARR has been shown to perform well for precipitation (i.e., have minimal bias; Kennedy et al. 2011). In addition, NARR surface-based variables were found to have comparable accuracy compared to other reanalysis datasets [e.g., the Modern-Era Retrospective Analysis for Research and Applications (MERRA) and the Climate Forecast System Reanalysis (CFSR); Santanello et al. 2015]. Studies have also utilized NARR land-based variables for climatological analysis (e.g., Miguez-Macho et al. 2008; Dominguez and Kumar 2008; Basara and Christian 2018). Because NARR has been shown to be sufficient in representing land-based variables, NARR was selected for application of the flash drought identification methodology and to produce a climatology of flash drought events across the United States. 


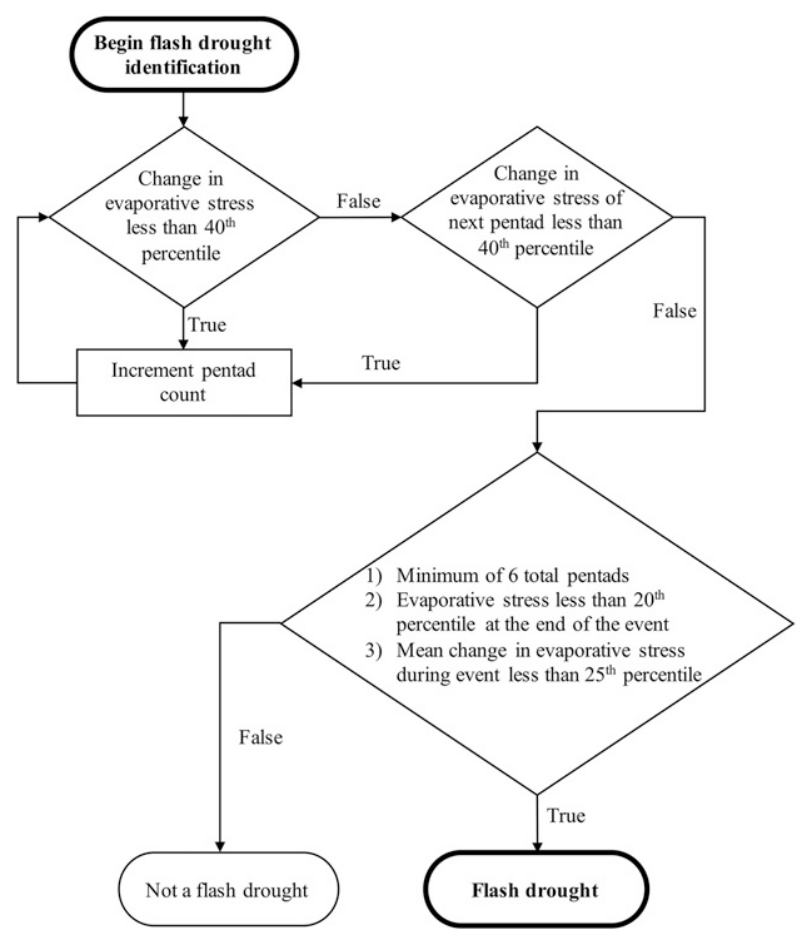

FIG. 3. A generalized flowchart of the flash drought identification methodology.

ET and PET from NARR between 1979 and 2016 were acquired for standardization and analysis following the methodology discussed in section 2. The Noah land surface model (LSM) in NARR uses soil evaporation, transpiration from the vegetation canopy, evaporation of dew/frost or canopy-intercepted precipitation, and snow sublimation as input for total surface ET (Mesinger et al. 2006). PET in NARR is calculated with the modified Penman scheme from Mahrt and Ek (1984). Flash droughts were examined during the approximate growing season (April-October) because rapid development of evaporative stress is less important outside of the growing season. In the winter months, ET is limited due to dormant vegetation and PET is small due to lower temperatures and lower net radiation. The combination of limited ET and PET restricts rapid changes in evaporative stress over an extended period of time, falling outside the definition of flash drought.

\section{b. Evaluation with the ESI}

Four case studies from Otkin et al. (2013) that identified flash droughts using the satellite-derived ESI were compared to the results from the methodology described in this study (Fig. 4). The first example assessed the evolution of a flash drought event over eastern Oklahoma and western Arkansas during 2000 (Fig. 4a). Evaporative stress values between the 2-week ESI composite from Otkin et al. (2013) and the SESR pentad analysis performed in this study were very similar, both temporally and in magnitude. The 2-week ESI and SESR began approximately at 0.6 and 0.4 , respectively, and ended at values near -1.4 and -2.2 , respectively. As for the timing, both analyses indicated the start of the flash drought near the end of July, with the conclusion of rapid drought development by the middle of September.

The second flash drought event that was examined occurred over eastern Indiana and western Ohio in 2007 (Fig. 4b). The 2-week ESI began to rapidly decrease around 15 April, while SESR started rapidly decreasing after 25 April. The end of the flash drought event (where evaporative stress values no longer rapidly decreased) occurred around 20 May for both ESI and SESR. While the beginning and ending values of ESI and SESR during the flash drought event were different the overall change in evaporative stress values during the event were very similar (approximately -1.7 for ESI and SESR).

In a flash drought event over southeastern Wisconsin in 2002, SESR produced results that compared poorly with ESI (Fig. 4c). Specifically, while SESR had decreased slightly between the end of June and early August, the rate of change of SESR was much smaller than the rate of change in ESI.

In the final case, a flash drought event in May/June of 2011 over a similar spatial domain as the first case was investigated (Fig. 4d). The 2-week ESI and SESR were very similar, with beginning values of -0.2 and 0.1 , respectively, and ending values of -1.8 and -1.5 , respectively. Timing was also comparable, with the beginning of the flash drought in late May for both analyses, and the end of the flash drought in late June/early July from the 2-week ESI and middle to late June from SESR.

While evaporative stress values between ESI and SESR were not identical in the four cases examined, a precise match between these two datasets is not expected as the standardized values of ESI and SESR were taken over different periods of record (2000-11 for ESI and 1979-2016 for SESR), SESR uses 5-day composites while ESI uses 2-week composites, and SESR is derived from modeled data while ESI is derived from satellitebased remote sensing observations. However, the similar timing and rate of change found between ESI and SESR increase the confidence that the NARR dataset can sufficiently represent evaporative stress and can be utilized for additional flash drought analysis.

\section{c. Evaluation with the U.S. Drought Monitor}

To further evaluate flash drought events identified in the NARR dataset, time series of SESR were compared with the USDM for four flash drought cases. 

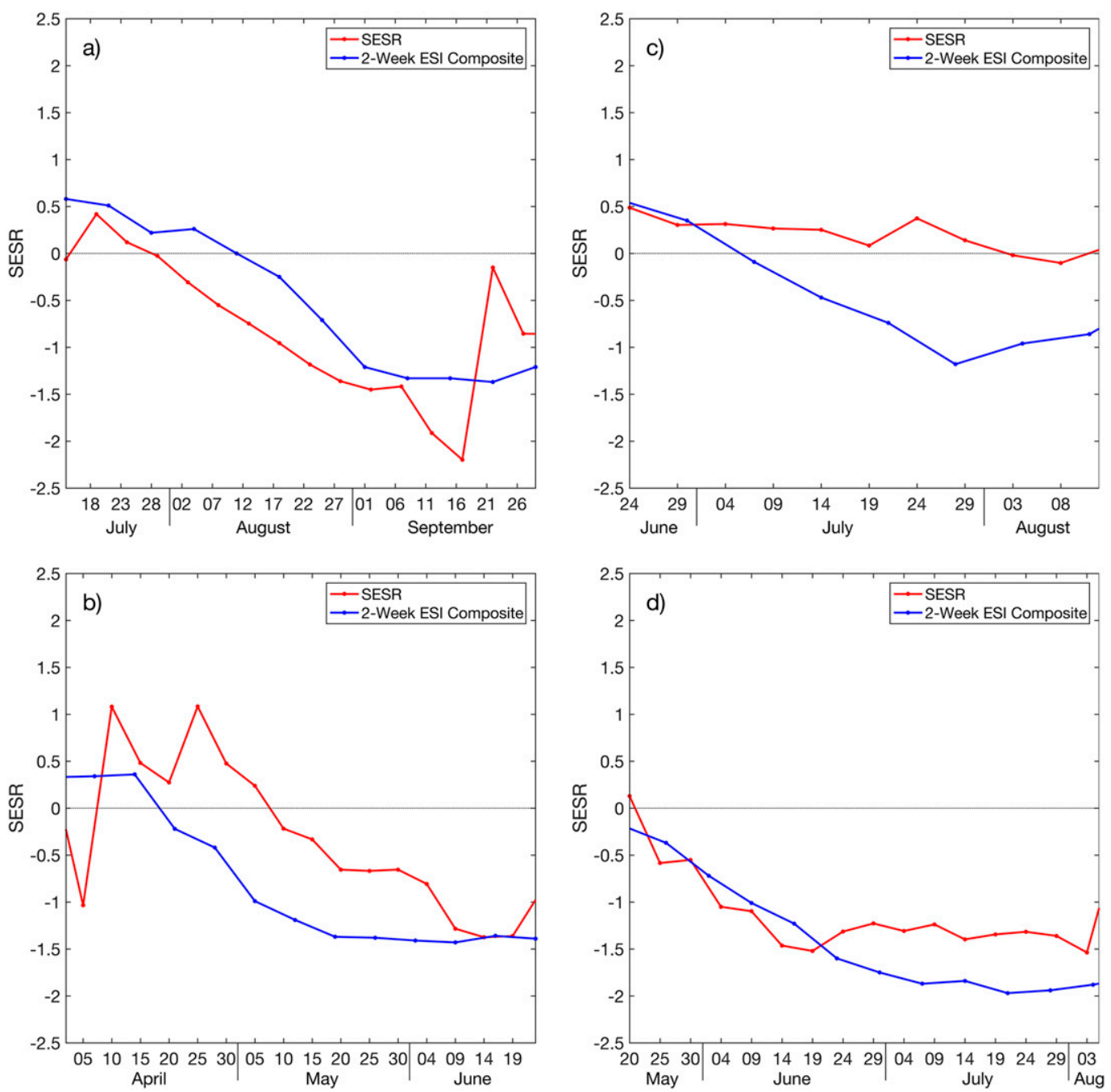

FIG. 4. SESR and 2-week ESI composites across (a) eastern Oklahoma and western Arkansas in 2000, (b) eastern Indiana and western Ohio in 2007, (c) southeastern Wisconsin in 2002, and (d) eastern Oklahoma and western Arkansas in 2011. Adapted from Otkin et al. (2013).

Spatial averages of SESR and the USDM were taken for each of the case study domains (the location and extent of the domains are shown in Fig. 5). The first flash drought event over Iowa in 2012 lasted for approximately 30 days between mid-June and mid-July (Fig. 6a). Preceding SESR values were slightly below normal (from -0.5 to -1.0 ) in May and early June before the rapid drought intensification began. The USDM values were initially category 0 before the flash drought event, but experienced over a two-category increase on average for the domain during the event. The second flash drought event over southeastern Minnesota and west central Wisconsin in 2008 is shown in Fig. 6b. Unlike the previous case, SESR values were near normal (approximately 0.3 ) before the rapid intensification period in late July and early August. This flash drought event also lasted approximately 30 days and underwent close to a two category change in the USDM. The 2016 flash drought over south central Georgia in Fig. 6c lasted approximately 35 days from late June to late July. Similar to the Minnesota/Wisconsin flash drought event, near-normal/above-average SESR existed before the rapid intensification period, however a moderation period was evident toward the end of the flash drought, with one positive $\triangle$ SESR in the middle of July. A nearly two-category degradation from the USDM was evident for this region in approximately 30 days. The final flash drought case that was examined occurred across eastern Kansas in 2003 (Fig. 6d). The rapid intensification period began in late June and lasted approximately 35 days. This region saw an average three-category degradation from the USDM in a span of only 35 days. 


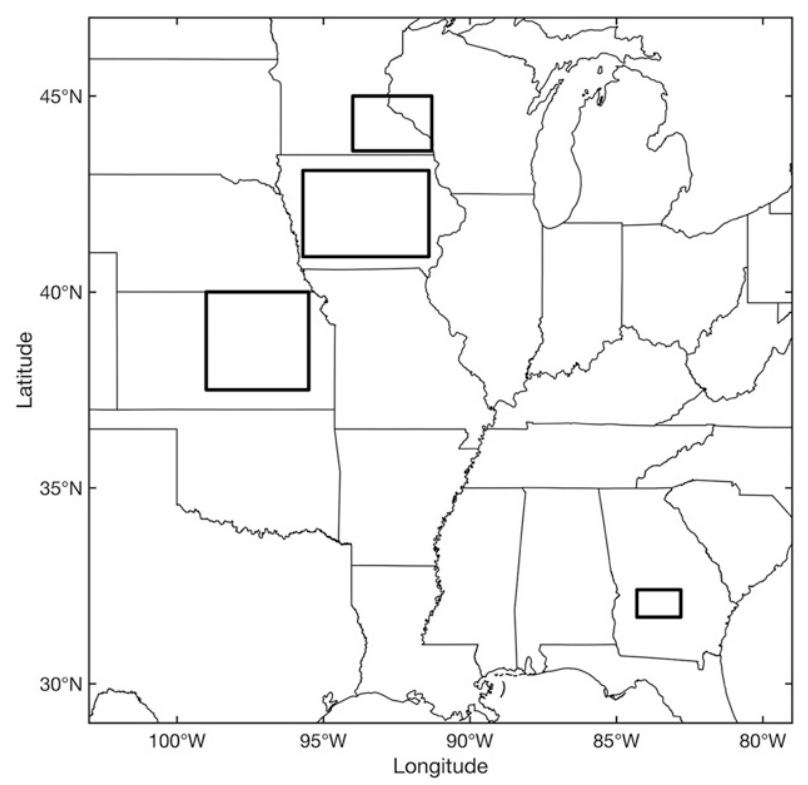

FIG. 5. The domains for the four flash drought cases shown in Fig. 6.

For each of the four cases, SESR rapidly declined 1-2 weeks before a response was evident with the USDM. This is similar to the results found in Otkin et al. (2013), where decreases in ESI preceded the USDM drought depiction by a couple of weeks.

\section{Application of the flash drought methodology}

\section{a. Flash drought frequency}

The flash drought methodology was applied to the NARR dataset to quantify the number of years that experienced a flash drought event (expressed as a percentage) across the United States (Fig. 7). Immediately apparent is the "hot spot" region of enhanced flash drought frequency over the Great Plains extending into the Corn Belt and western Great Lakes region. In these regions, flash droughts occurred in approximately $40 \%$ of the years in the NARR dataset. Local hot spots also exist over the Mississippi Embayment and across the Atlantic coastal plain, with approximately $30 \%-40 \%$ of the years containing a flash drought event at these locations. In contrast, regions of less frequent flash drought occurrence were evident across the Northwest, Southwest, Rocky Mountains, Ozarks, and Appalachian Mountains. Flash droughts occurred approximately between $10 \%$ and $20 \%$ of the total years on record in the NARR dataset in these areas.

\section{b. Flash drought intensity}

Flash droughts were categorized by their rate of intensification using the mean SESR change ( $\triangle$ SESR) during the flash drought. A flash drought intensity index was developed that includes four categories (FD1, FD2, FD3, and FD4) ranging from relatively slowerdeveloping flash droughts (i.e., FD1) to the most rapidly developing flash droughts (i.e., FD4). Although flash droughts are partitioned based on the speed with which they developed, it is critical to note that all flash droughts, regardless of category, are extreme phenomena. The percentile thresholds used for each category are shown in Table 1 . The percentiles were selected to loosely follow the percentiles used in the USDM, however the percentiles were $5 \%-10 \%$ greater than those used in the USDM (D1-D4). This is due to the fact that the USDM uses percentiles for individual moments of time (i.e., drought conditions for a specific week). Requiring a variable (such as SESR) to decline at USDM percentiles (i.e., 20th, 10th, 5th, 2nd) for several consecutive pentads is statistically rare and would likely miss the capture of many rapid intensification periods that produce impacts associated with a flash drought event. The primary focus of the flash drought intensity nomenclature is to categorize the rapid development of flash droughts with limited emphasis on the final severity of the flash drought. While terminating in drought conditions is an essential component of flash droughts, it is the rapid onset and development of drought that separates flash droughts from slowly developing drought conditions.

The frequencies of different flash drought intensities are shown in Fig. 8. Beginning with FD1 (moderate flash droughts), flash droughts in this category occur most frequently across the entire north-south extent of the Great Plains. A similar signal is evident for FD2 flash droughts (severe flash droughts), with the highest flash drought frequency occurring in the southern and central Great Plains, as well as through the Corn Belt. In addition, portions of the Atlantic coastal plain have hot spots of flash drought frequency in the FD2 category. For extreme flash droughts (FD3), the signal becomes especially refined in the primary flash drought hot spot locations of the central Great Plains and Corn Belt, as well as portions of the Atlantic coastal plain. Last, exceptional flash droughts (FD4) exist almost exclusively across the central Great Plains, Corn Belt, western Great Lakes region, and the Atlantic coastal plain.

\section{Discussion}

The primary purpose of this study was to present an objective methodology to identify flash drought events in gridded datasets using ET-based variables. The methodology provided here is complementary to the general flash drought definition provided by Otkin et al. (2018a). 

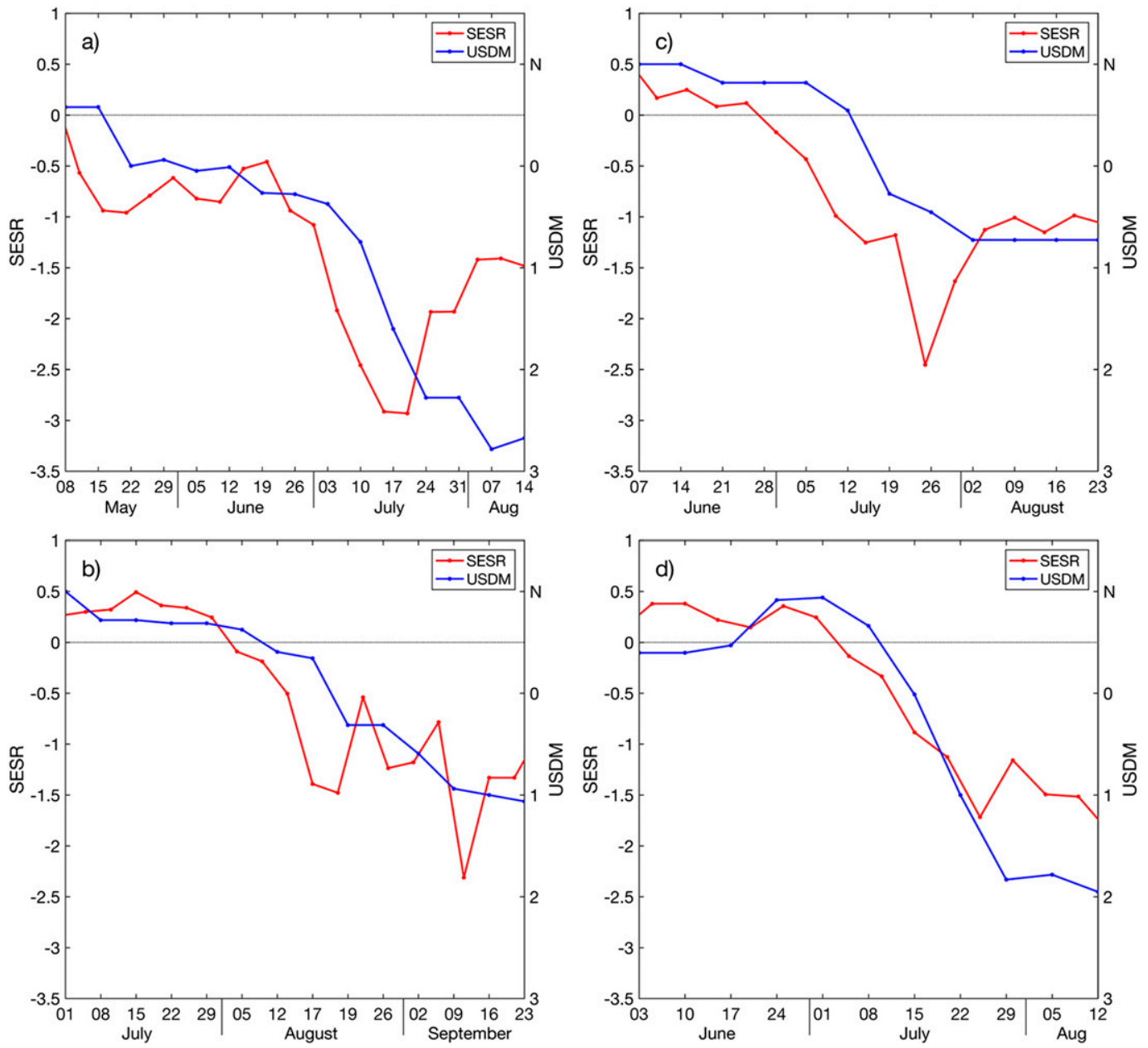

FIG. 6. SESR and the USDM for a flash drought event over (a) Iowa in 2012, (b) southeastern Minnesota and west-central Wisconsin in 2008, (c) south-central Georgia in 2016, and (d) eastern Kansas in 2003.

Each component of the flash drought methodology developed during this study, including rapid drought development, drought conditions at the end of the rapid intensification period, and longevity, follows the guidelines presented in Otkin et al. (2018a). While this methodology can be readily applied to gridded datasets, it can also be used in local analyses as well, such as with flux tower/ mesonet observations provided that a long enough period of observations is available for standardization and measurements/calculations of ET/PET. Furthermore, while the primary focus of the methodology was for flash drought identification, the methodology could also be leveraged for flash drought monitoring. Similar to how the U.S. Drought Monitor portrays information on drought conditions across the United States, the flash drought methodology presented here could be used to reveal regions that are currently experiencing or have experienced a flash drought.

SESR values derived from NARR analyses were used to examine individual flash drought examples and to quantify climatological characteristics of flash droughts across the United States. The four SESR time series examples provided in Fig. 6 illustrate how flash droughts can develop either with monotonically decreasing SESR (Figs. 6a,b,d; based solely on criterion 3a in section 2b) or with the inclusion of a short moderation period in SESR (Fig. 6c; utilizing criterion $3 b$ in section 2b). From the analysis of flash drought frequency in section $4 \mathrm{a}$ (Fig. 7), partitioning the identified flash droughts into flash droughts that used only criterion $3 \mathrm{a}$ and flash droughts that used both criterion $3 \mathrm{a}$ and $3 \mathrm{~b}$ revealed that $24 \%$ of all flash drought events were the monotonic decrease case and $76 \%$ of all flash drought events included significant but temporary moderation. A more thorough investigation of this partitioning, however, will be a topic of future research.

The results from the climatological frequency of flash droughts revealed a significant "hot spot" of greater flash drought occurrence across the Great Plains, Corn 


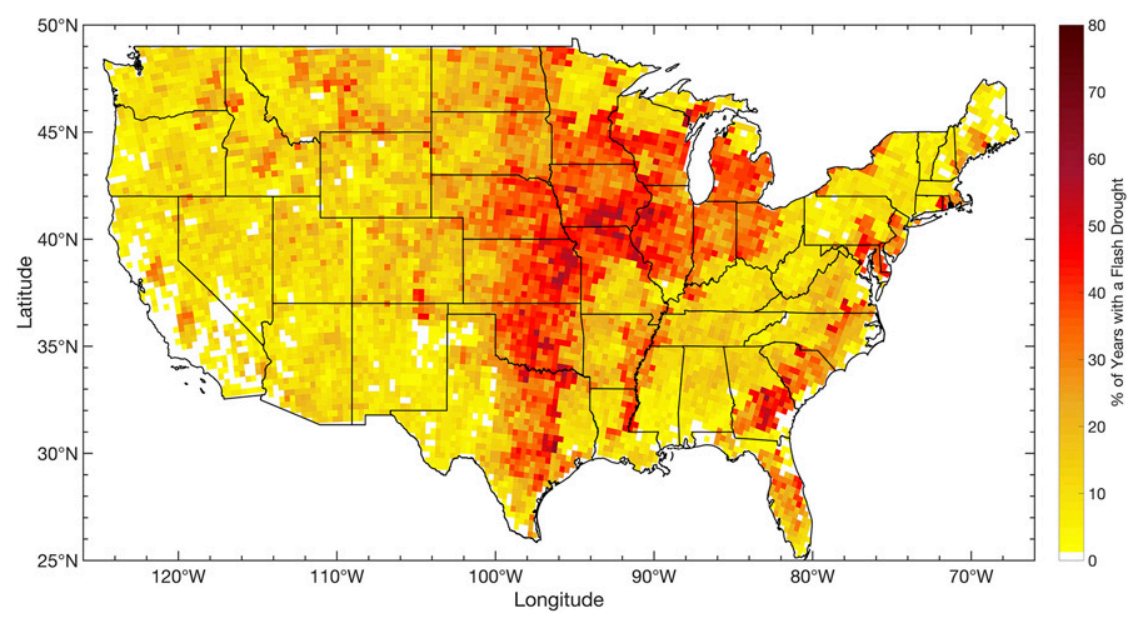

FIG. 7. Percent of years in the NARR dataset between 1979 and 2016 with a flash drought. Flash droughts were identified using the flash drought identification methodology in section $2 b$.

Belt, and western Great Lakes region. Two key characteristics of these regions might be contributing to the maxima in flash drought frequency: agriculture and land-atmosphere coupling. The representation of vegetative differences in NARR is via the NCEP Eta Model. Thirteen vegetative types are prescribed in the Eta model, including a category for cultivations. Agricultural regions may be more susceptible to flash drought due to a shallower root zone and a higher rate of ET (soil moisture depletion) relative to natural grassland. The second factor that may lead to increased flash drought frequency is land-atmosphere coupling. The Great Plains has been identified by several studies as a hot spot for land-atmosphere coupling (Koster et al. 2004; Dirmeyer 2011; Basara and Christian 2018). Semiarid regions such as the Great Plains show greater sensitivity of surface fluxes and ET to changes in soil moisture (Guo et al. 2006; Dirmeyer 2006; Wei et al. 2016). As soil moisture decreases, ET is reduced, which limits the availability of locally sourced boundary layer moisture. In the absence of significant moisture advection, the atmosphere continues to dry and increases evaporative demand. This results in a positive feedback in which dry soils modify the environment and make it less favorable for convective precipitation (Findell and Eltahir 2003a,b; Pielke 2001). Such positive feedbacks due to land-atmosphere coupling could serve to accelerate decreases in SESR and may be a key contributor to the greater frequency of flash droughts observed in the Great Plains.

Regions with a lower frequency in flash drought occurrence were also identified from the climatological analysis of flash droughts. These regions primarily existed over arid, high-elevation, or forested regions. Three main factors could contribute to a lack of flash drought events in these regions: 1) lack of available water in the soil profile, 2) sparse vegetation, and $3)$ vegetation type. Even when rainfall occurs in arid locations, limited soil moisture capacity prevents the wetting of the environment toward semiarid or dry subhumid conditions. Furthermore, transitions from limited evaporative stress to strong evaporative stress over an extended period of time in these regions are less likely due to a lack of available water in the soil profile. The second potential contributing factor to minima in flash drought occurrence is sparse vegetation. This mostly includes high-elevation regions (e.g., the Rocky Mountains) or desert locations. With minimal vegetation, transpiration is limited and leads to restricted ET. To obtain a rapid change in SESR for flash drought development, a rapid decrease in ET is required (in conjunction with a rapid increase in PET). Furthermore, regions of sparse vegetation will likely have short periods of declining SESR. For example, the Mojave Desert can receive an abundance of rain during the monsoon. This will ultimately lead to frequent large spikes in ET followed by a large decrease in ET due to the large evaporative demand. However, this transition from minimal evaporative stress to large evaporative stress would likely happen during a short time period (i.e., one or two pentads). These short transitions from

TABLE 1. Mean change in SESR thresholds for the categorization of flash drought intensity.

\begin{tabular}{cll}
\hline \hline $\begin{array}{c}\text { Flash drought } \\
\text { intensity index }\end{array}$ & Flash drought intensity & Mean change in SESR \\
\hline FD1 & Moderate flash drought & 20th-25th percentile \\
FD2 & Severe flash drought & 15th-20th percentile \\
FD3 & Extreme flash drought & 10th-15th percentile \\
FD4 & Exceptional flash drought & $<$ 10th percentile \\
\hline
\end{tabular}



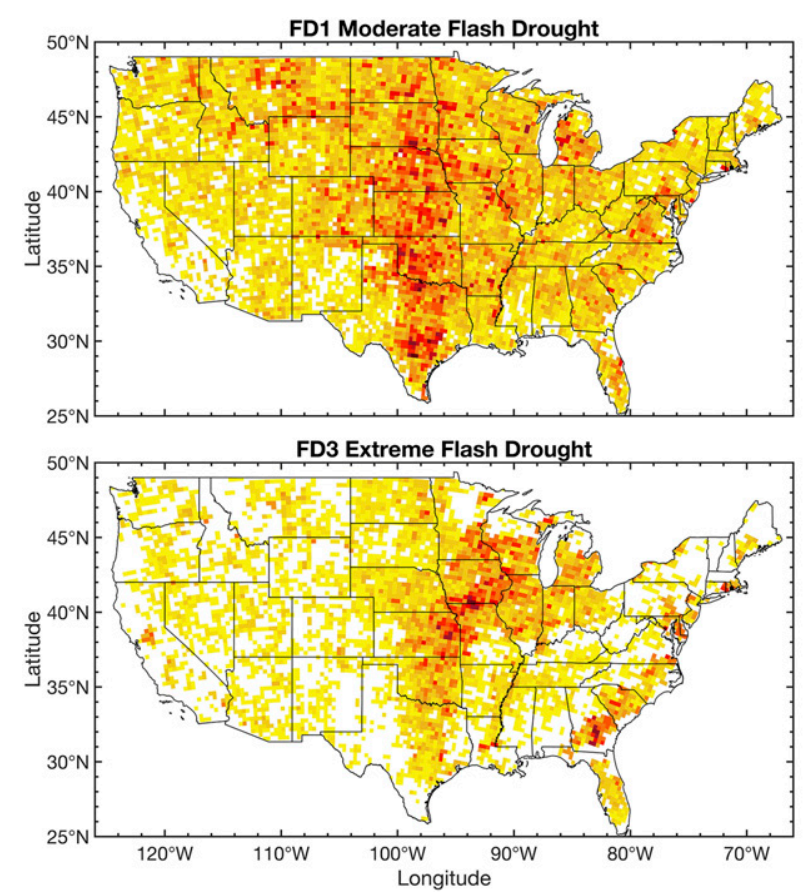

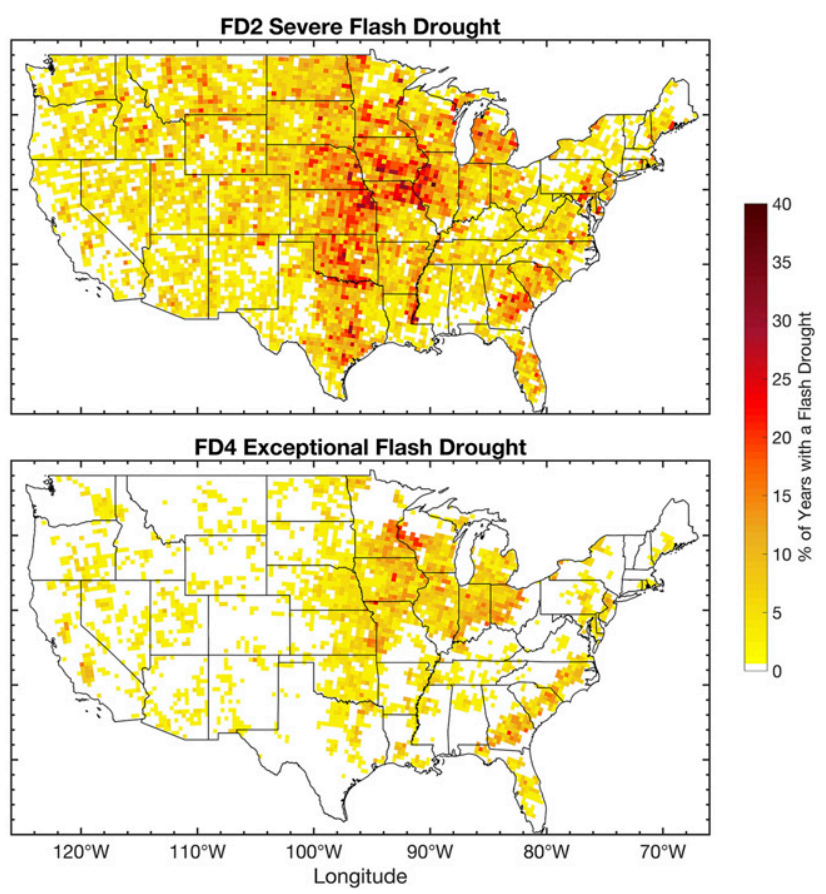

FIG. 8. Percent of years in the NARR dataset between 1979 and 2016 with a flash drought categorized by their intensity. Flash droughts were identified using the flash drought identification methodology in section $2 \mathrm{~b}$. See Table 1 for percentile thresholds of each category.

minimal evaporative stress to large evaporative stress would not meet the criteria or definition for an agricultural flash drought. Last, vegetation type can also play a critical role in inhibiting flash drought development. For example, in forested regions, such as the Ozarks and Appalachian Mountains, deeper root zones can access more subsoil moisture, precluding a rapid increase in evaporative stress.

In section $4 \mathrm{~b}$, flash droughts were partitioned by their rate of intensification, following a categorization similar to that used by the Drought Monitor (Svoboda et al. 2002). The agricultural regions across the United States (central Great Plains, Corn Belt, and portions of the Atlantic coastal plain) emerged as a significant hot spot for the most rapidly developing flash droughts (FD3/ FD4; Fig. 8). This supports the hypothesis previously discussed, where regions with crops act as an accelerant for changes in evaporative stress, and as such, lead to the most intense flash droughts. Furthermore, while moderate and severe flash droughts are possible in any region across the United States, hot spots of flash drought frequency in the FD1 and FD2 categories were still seen across the Great Plains and Corn Belt. This implies that while flash droughts can develop over other vegetation types (grasslands, forests, etc.), agricultural regions tend to contain a higher frequency of flash droughts of any intensity.

The methodology presented in this study provides objective identification of flash drought events. However, it is important to be cognizant of two artifacts resulting from this methodology. First, while the methodology performed well with the individual flash drought cases and the climatological analyses in this study, it is possible that changes in SESR could be dependent on the LSM used by different reanalysis datasets. Grid point by grid point daily standardization of ESR provided in section 2a should largely account for these differences as long as the LSM still captures the variability in ET and PET, but variations in the distribution of $\triangle$ SESR among different datasets could make the 40th-percentile-based methodology presented in this study (in conjunction with the minimum 25th percentile change in evaporative stress over the entire length of the flash drought) too strict or too loose. However, it was ultimately shown that, through the standardization process in section 2a, SESR values and change values from a reanalysis dataset (NARR) compared well with the ESI, which has been shown in prior studies to accurately capture the evolution of flash droughts as well as the USDM. This provides confidence that the given methodology should be able to account for differences between datasets satisfactorily for application across a diverse set of datasets.

The second limitation is inherent in the development of any objective-based methodology for flash drought identification. That is, identifying features that are not actually flash drought events and not identifying features that are actually flash drought events. From an 
objective standpoint, this requires an upper bound and a lower bound to identify flash droughts. To illustrate, we allow the upper bound to represent the identification of features that are not flash droughts (i.e., false alarm; too many flash droughts identified) and the lower bound to represent missed identification of features that are flash droughts (i.e., misses; too few flash droughts identified). The methodology presented in this study provides a cap for the upper bound of flash drought identification by placing four criteria to capture flash drought events. The four criteria in section $2 \mathrm{~b}$ emphasize the minimum requirements for a flash drought event, pertaining to the rate of intensification and impact of flash droughts [following the guidelines presented in Otkin et al. (2018a)]. However, the lower bound of flash drought identification (missing the identification of flash drought events) can be partially subjective. For example, in the inclusion of periods of moderation within the methodology, moderation could be adjusted to include up to two or three pentads before continuing the rapid intensification of evaporative stress toward drought. Even so, the authors believe that including a moderation period this large in the objective flash drought methodology could mistakenly identify features that take several months to develop as "flash droughts" when instead they more closely fit the definition of conventional slower developing droughts.

Finally, additional reanalysis datasets exist with varying spatial resolution, for instance, phase 2 of the North American Land Data Assimilation System (NLDAS-2; Xia et al. 2012) and MERRA, version 2 (MERRA-2; Gelaro et al. 2017). Future work will examine the impact of the resolution of the LSM on the variability of the drivers associated with flash drought and flash drought identification. While beyond the scope of this study, scalability of flash drought identification among datasets is critical and will be a topic of future research.

\section{Conclusions}

This study follows upon the proposed flash drought definition provided in Otkin et al. (2018a) in which flash droughts are identified based on their rapid rate of intensification. Two major components were discussed: a methodology for flash drought identification and application of the methodology to a reanalysis dataset. A percentile-based methodology for flash drought identification was developed utilizing standardized anomalies of evaporative stress. The proposed flash drought identification methodology emphasizes vegetative impact and rapid rate of intensification from flash drought. Two criteria in the identification methodology incorporate vegetative impacts by separating dry spells from flash droughts and ensuring that a flash drought event ends in drought conditions. Two additional criteria emphasize the rapid rate of drought intensification, with one criterion focused on pentad-to-pentad changes in evaporative stress, and the other criterion focused on the rate of change in evaporative stress through the entire length of the flash drought event.

Values of SESR from the NARR were compared with ESI values from satellite-based thermal infrared observations and were found to have comparable timing and rate of change in evaporative stress. A climatological analysis of flash drought events in the NARR dataset from 1979 to 2016 revealed a hot spot of flash drought events over the Great Plains, Corn Belt, and western Great Lakes region. Flash droughts were partitioned by intensity (rate of intensification) and revealed that flash droughts with the largest rate of intensification occurred across the central Great Plains, Corn Belt, and western Great Lakes region.

With the flash drought methodology presented in this study, future work will investigate flash drought climatologies using other reanalysis and observational datasets. Furthermore, the initial climatological results indicate that future work is also needed to examine regional characteristics of flash droughts across the United States.

Acknowledgments. This work was supported, in part, by the NOAA Climate Program Office's Sectoral Applications Research Program (SARP) Grant NA130AR4310122, the Agriculture and Food Research Initiative Competitive Grant 2012-02355 from the USDA National Institute of Food and Agriculture, the USDA National Institute of Food and Agricultural (NIFA) Grant 2016-68002-24967, the USDA Southern Great Plains Climate Hub, and the NASA SMD Earth Science Division through the Earth Science Application: Water Resources Program.

\section{REFERENCES}

Anderson, M. C., J. M. Norman, J. R. Mecikalski, J. A. Otkin, and W. P. Kustas, 2007a: A climatological study of evapotranspiration and moisture stress across the continental United States based on thermal remote sensing: 1. Model formulation. J. Geophys. Res., 112, D10117, https://doi.org/10.1029/2006JD007506.

,,,,---- and,$- 2007 \mathrm{~b}$ : A climatological study of evapotranspiration and moisture stress across the continental United States based on thermal remote sensing: 2. Surface moisture climatology. J. Geophys. Res., 112, D11112, https:// doi.org/10.1029/2006JD007507.

_ C. C. R. Hain, B. Wardlow, J. R. Mecikalski, and W. P. Kustas, 2011: Evaluation of drought indices based on thermal remote sensing of evapotranspiration over the continental United States. J. Climate, 24, 2025-2044, https://doi.org/ 10.1175/2010JCLI3812.1.

—_, C. Hain, J. Otkin, X. Zhan, K. Mo, M. Svoboda, B. Wardlow, and A. Pimstein, 2013: An intercomparison of 
drought indicators based on thermal remote sensing and NLDAS-2 simulations with U.S. Drought Monitor classifications. J. Hydrometeor., 14, 1035-1056, https://doi.org/ 10.1175/JHM-D-12-0140.1.

_ C. A. Zolin, C. R. Hain, K. Semmens, M. Tugrul Yilmaz, and F. Gao, 2015: Comparison of satellite-derived LAI and precipitation anomalies over Brazil with a thermal infrared-based Evaporative Stress Index for 2003-2013. J. Hydrol., 526, 287-302, https://doi.org/10.1016/j.jhydrol.2015.01.005.

— , and Coauthors, 2016a: The Evaporative Stress Index as an indicator of agricultural drought in Brazil: An assessment based on crop yield impacts. Remote Sens. Environ., 174, 82-99, https://doi.org/10.1016/j.rse.2015.11.034.

_ tive Stress Index and winter wheat and spring barley yield anomalies in the Czech Republic. Climate Res., 70, 215-230, https://doi.org/10.3354/cr01411.

Basara, J. B., and J. I. Christian, 2018: Seasonal and interannual variability of land-atmosphere coupling across the Southern Great Plains of North America using the North American regional reanalysis. Int. J. Climatol., 38, 964-978, https:// doi.org/10.1002/joc.5223.

_ J. N. Maybourn, C. M. Peirano, J. E. Tate, P. J. Brown, J. D. Hoey, and B. R. Smith, 2013: Drought and Associated Impacts in the Great Plains of the United States-A Review. Int. J. Geosci., 4, 72-81, https://doi.org/10.4236/ijg.2013.46A2009.

Chang, F.-C., and J. M. Wallace, 1987: Meteorological conditions during heat waves and droughts in the United States Great Plains. Mon. Wea. Rev., 115, 1253-1269, https:// doi.org/10.1175/1520-0493(1987)115<1253:MCDHWA> 2.0.CO;2.

Diaz, H. F., 1983: Drought in the United States. J. Climate Appl. Meteor., 22, 3-16, https://doi.org/10.1175/1520-0450(1983) 022<0003:DITUS $>2.0$.CO;2.

Dirmeyer, P. A., 2006: The hydrologic feedback pathway for landclimate coupling. J. Hydrometeor., 7, 857-867, https://doi.org/ 10.1175/JHM526.1.

_ 2011: The terrestrial segment of soil moisture-climate coupling. Geophys. Res. Lett., 38, L16702, https://doi.org/10.1029/ 2011 GL048268.

Dominguez, F., and P. Kumar, 2008: Precipitation recycling variability and ecoclimatological stability-A study using NARR data. Part I: Central U.S. plains ecoregion. J. Climate, 21, 5165-5186, https://doi.org/10.1175/2008JCLI1756.1.

Findell, K. L., and E. A. B. Eltahir, 2003a: Atmospheric controls on soil moisture-boundary layer interactions. Part I: Framework development. J. Hydrometeor., 4, 552-569, https://doi.org/ 10.1175/1525-7541(2003)004<0552:ACOSML > 2.0.CO;2.

$\longrightarrow$, and —, 2003b: Atmospheric controls on soil moistureboundary layer interactions. Part II: Feedbacks within the continental United States. J. Hydrometeor., 4, 570-583, https:// doi.org/10.1175/1525-7541(2003)004<0570:ACOSML>2.0.CO;2.

Ford, T. W., and C. F. Labosier, 2017: Meteorological conditions associated with the onset of flash drought in the eastern United States. Agric. For. Meteor., 247, 414-423, https://doi.org/10.1016/ j.agrformet.2017.08.031.

Gelaro, R., and Coauthors, 2017: The Modern-Era Retrospective Analysis for Research and Applications, version 2 (MERRA-2). J. Climate, 30, 5419-5454, https://doi.org/ 10.1175/JCLI-D-16-0758.1.

Griffin, D., and K. J. Anchukaitis, 2014: How unusual is the 20122014 California drought? Geophys. Res. Lett., 41, 9017-9023, https://doi.org/10.1002/2014GL062433.
Guo, Z., and Coauthors, 2006: GLACE: The Global LandAtmosphere Coupling Experiment. Part II: Analysis. $J$. Hydrometeor., 7, 611-625, https://doi.org/10.1175/JHM511.1.

Hobbins, M. T., A. Wood, D. J. McEvoy, J. L. Huntington, C. Morton, M. Anderson, and C. Hain, 2016: The Evaporative Demand Drought Index. Part I: Linking drought evolution to variations in evaporative demand. J. Hydrometeor., 17, 1745-1761, https://doi.org/10.1175/JHM-D-15-0121.1.

Kennedy, A. D., X. Dong, B. Xi, S. Xie, Y. Zhang, and J. Chen, 2011: A comparison of MERRA and NARR reanalyses with the DOE ARM SGP data. J. Climate, 24, 4541-4557, https:// doi.org/10.1175/2011JCLI3978.1.

Koster, R. D., and Coauthors, 2004: Regions of strong coupling between soil moisture and precipitation. Science, 305, 11381140, https://doi.org/10.1126/science.1100217.

Krishnan, P., T. A. Black, N. J. Grant, A. G. Barr, E. T. H. Hogg, R. S. Jassal, and K. Morgenstern, 2006: Impact of changing soil moisture distribution on net ecosystem productivity of a boreal aspen forest during and following drought. Agric. For. Meteor., 139, 208-223, https://doi.org/10.1016/j.agrformet.2006.07.002.

Mahrt, L., and M. Ek, 1984: The influence of atmospheric stability on potential evaporation. J. Climate Appl. Meteor., 23, 222-234, https://doi.org/10.1175/1520-0450(1984)023<0222: TIOASO $>2.0 . \mathrm{CO} ; 2$.

Manuel, J., 2008: Drought in the southeast: Lessons for water management. Environ. Health Perspect., 116, A168-A171, https://doi.org/10.1289/ehp.116-a168

McCabe, G. J., J. L. Betancourt, S. T. Gray, M. A. Palecki, and H. G. Hidalgo, 2008: Associations of multi-decadal sea-surface temperature variability with US drought. Quat. Int., 188, 31-40, https://doi.org/10.1016/j.quaint.2007.07.001.

McEvoy, D. J., J. L. Huntington, M. T. Hobbins, A. Wood, C. Morton, M. Anderson, and C. Hain, 2016: The Evaporative Demand Drought Index. Part II: CONUS-wide assessment against common drought indicators. J. Hydrometeor., 17, 1763-1779, https://doi.org/10.1175/JHM-D-15-0122.1.

Mesinger, F., and Coauthors, 2006: North American Regional Reanalysis. Bull. Amer. Meteor. Soc., 87, 343-360, https:// doi.org/10.1175/BAMS-87-3-343.

Miguez-Macho, G., H. Li, and Y. Fan, 2008: Simulated water table and soil moisture climatology over North America. Bull. Amer. Meteor. Soc., 89, 663-672, https://doi.org/10.1175/BAMS-89-5-663.

Mo, K. C., and D. P. Lettenmaier, 2015: Heat wave flash droughts in decline. Geophys. Res. Lett., 42, 2823-2829, https://doi.org/ 10.1002/2015GL064018.

- and - 2016: Precipitation deficit flash droughts over the United States. J. Hydrometeor., 17, 1169-1184, https://doi.org/ 10.1175/JHM-D-15-0158.1.

Otkin, J. A., M. C. Anderson, C. Hain, I. E. Mladenova, J. B. Basara, and M. Svoboda, 2013: Examining rapid onset drought development using the thermal infrared-based Evaporative Stress Index. J. Hydrometeor., 14, 1057-1074, https://doi.org/ 10.1175/JHM-D-12-0144.1.

,,--- , and M. Svoboda, 2014: Examining the relationship between drought development and rapid changes in the Evaporative Stress Index. J. Hydrometeor., 15, 938-956, https://doi.org/10.1175/JHM-D-13-0110.1.

-, and Coauthors, 2016: Assessing the evolution of soil moisture and vegetation conditions during the 2012 United States flash drought. Agric. For. Meteor., 218-219, 230-242, https://doi.org/ 10.1016/j.agrformet.2015.12.065.

M. Svoboda, E. D. Hunt, T. W. Ford, M. C. Anderson, C. Hain, and J. B. Basara, 2018a: Flash droughts: A review and 
assessment of the challenges imposed by rapid-onset droughts in the United States. Bull. Amer. Meteor. Soc., 99, 911-919, https://doi.org/10.1175/BAMS-D-17-0149.1.

—, T. Haigh, A. Mucia, M. C. Anderson, and C. R. Hain, 2018b: Comparison of agricultural stakeholder survey results and drought monitoring datasets during the 2016 U.S. northern plains flash drought. Wea. Climate Soc., 10, 867-883, https:// doi.org/10.1175/WCAS-D-18-0051.1.

— , Y. Zhong, E. D. Hunt, J. Basara, M. Svoboda, M. C. Anderson, and C. R. Hain, 2019: Assessing the evolution of soil moisture and vegetation conditions during a flash drought-flash recovery sequence over the south-central United States. J. Hydrometeor., 20, 549-562, https://doi.org/10.1175/JHM-D-18-0171.1.

Pielke, R. A., Sr., 2001: Influence of the spatial distribution of vegetation and soils on the prediction of cumulus Convective rainfall. Rev. Geophys., 39, 151-177, https://doi.org/10.1029/ 1999RG000072.

Santanello, J. A., Jr., J. Roundy, and P. A. Dirmeyer, 2015: Quantifying the land-atmosphere coupling behavior in modern reanalysis products over the U.S. Southern Great Plains. J. Climate, 28, 5813-5829, https://doi.org/10.1175/JCLI-D-14-00680.1.

Svoboda, M., and Coauthors, 2002: The Drought Monitor. Bull. Amer. Meteor. Soc., 83, 1181-1190, https://doi.org/10.1175/ 1520-0477-83.8.1181.

Thacker, M. T. F., R. Lee, R. I. Sabogal, and A. Henderson, 2008: Overview of deaths associated with natural events, United States, 1979-2004. Disasters, 32, 303-315, https://doi.org/ 10.1111/j.1467-7717.2008.01041.x.

Wang, L., X. Yuan, Z. Xie, P. Wu, and Y. Li, 2016: Increasing flash droughts over China during the recent global warming hiatus. Sci. Rep., 6, 30571, https://doi.org/10.1038/srep30571.

Wei, J., H. Su, and Z.-L. Yang, 2016: Impact of moisture flux convergence and soil moisture on precipitation: a case study for the southern United States with implications for the globe.
Climate Dyn., 46, 467-481, https://doi.org/10.1007/s00382-0152593-2.

Westerling, A. L., and T. W. Swetnam, 2003: Interannual to decadal drought and wildfire in the western United States. Eos, Trans. Amer. Geophys. Union, 84, 545-555, https://doi.org/ 10.1029/2003EO490001.

Wilhite, D. A., 2000: Drought as a natural hazard: Concepts and definitions. Drought: A Global Assessment, D. A. Wilhite, Ed., Routledge, 3-18, .

—, and M. H. Glantz, 1985: Understanding: The drought phenomenon: The Role of definitions. Water Int., 10, 111-120, https://doi.org/10.1080/02508068508686328.

— M. D. Svoboda, and M. J. Hayes, 2007: Understanding the complex impacts of drought: A key to enhancing drought mitigation and preparedness. Water Resour. Manage., 21, 763-774, https://doi.org/10.1007/s11269-006-9076-5.

Xia, Y., and Coauthors, 2012: Continental-scale water and energy flux analysis and validation for the North American Land Data Assimilation System project phase 2 (NLDAS-2): 1. Intercomparison and application of model products. J. Geophys. Res., 117, D03109, https://doi.org/10.1029/2011JD016048.

Yuan, X., L. Wang, and E. F. Wood, 2018: Anthropogenic intensification of Southern African flash droughts as exemplified by the 2015/16 season. Bull. Amer. Meteor. Soc., 99, S86-S90, https://doi.org/10.1175/BAMS-D-17-0077.1.

Zhang, Y., Q. You, C. Chen, and X. Li, 2017: Flash droughts in a typical humid and subtropical basin: A case study in the Gan River Basin, China. J. Hydrol., 551, 162-176, https://doi.org/ 10.1016/j.jhydrol.2017.05.044.

Zou, Z., X. Xiao, J. Dong, Y. Qin, R. B. Doughty, M. A. Menarguez, G. Zhang, and J. Wang, 2018: Divergent trends of open-surface water body area in the contiguous United States from 1984 to 2016. Proc. Natl. Acad. Sci. USA, 115, 3810-3815, https://doi.org/10.1073/pnas.1719275115. 